\title{
Comparing Reinforcement Options for the Staple Line of Laparoscopic Sleeve Gastrectomy
}

\author{
Mehmet Bayrak1 and Yasemin Altintas²
}

\begin{abstract}
Objective: To compare three reinforcement options (suture, fibrin glue, and no reinforcement) for staple line reinforcement of patients undergoing laparoscopic sleeve gastrectomy.

Study Design: An experimental study.

Place and Duration of Study: Ortadogu Hospital, Adana, Turkey, from 2013 to 2017.

Methodology: The inclusion criteria were patients with $\mathrm{BMI}>40 \mathrm{Kg} / \mathrm{m}^{2}$ or $>35 \mathrm{Kg} / \mathrm{m}^{2}$ (if there were comorbid diseases associated with obesity). The exclusion criteria were patients who were older than 65 years or had a bariatric procedure earlier. The patients were placed in three groups. Group 1 had no staple line reinforcement, group 2 had fibrin glue on the staple line, and group 3 had barbed continued suture on the staple line. The primary endpoints included stenosis, bleeding, and postoperative leaks. The secondary outcomes included total operation time and time for staple line reinforcement. Values of $p<0.05$ were deemed significant for all statistical tests.

Results: The mean time to perform the staple line reinforcement was significantly higher in group 3 (22.05 \pm 2.83 minutes) than in group 2 (fibrin glue, $10.86 \pm 2.15$ minutes, $p<0.001$ ). The mean total operation times were significantly different between all three groups; $70.8 \pm 5.4$ minutes for group 1, $74.7 \pm 6.2$ minutes for group 2 , and $81.2 \pm 3.0$ minutes for group 3 ( $p<0.001)$. The groups had no statistical differences regarding complications.

Conclusion: The use of fibrin glue and barbed continuous suture for staple line reinforcement during laparoscopic sleeve gastrectomy had no effect on post- or per-operative hemorrhage and leakage; however, these procedures significantly extended the operation time.
\end{abstract}

Key Words: Laparoscopic sleeve gastrectomy, Reinforcement, Fibrin glue, V lock.

\section{INTRODUCTION}

Laparoscopic sleeve gastrectomy (LSG) effectively reduces weight-related morbidity and is useful for losing weight in the short-to-mid term. ${ }^{1-4}$ LSG was initially performed as a bridge procedure for biliopancreatic diversion (with duodenal switch) or for laparoscopic Roux-en-Y gastric bypass. ${ }^{5-7}$ Although surgical staplers are continually improving, LSG's main postoperative complications are staple-line (SL) leaks and bleeding. 8-10 In order to strengthen the staple line, surgeons may utilise buttressing, gelatin matrix agents and/or fibrin sealant, and clips and sutures; these all can lead to reductions in complications and better hemostasis. ${ }^{11-14}$ The overall mortality of LSG is $0.3 \%$, and the procedure's leak-related mortality is $0.1 \% .^{2}$ However, the incidence of staple line leak ranges from $0.0-5.5 \%$ and they are caused by an increase in intraluminal pressure, which is enough to exceed the resistance of the tissue and suture-line. ${ }^{15}$

While many surgeons strengthen the staple line during LSG, its effect is still controversial. The aim of this study

Department of General Surgeryl / Radiology2, Ortadogu Hospital, Adana, 01360, Turkey

Correspondence: Dr. Mehmet Bayrak, Department of General Surgery, Ortadogu Hospital, Adana, 01360, Turkey

E-mail:drmehmetbayrak@hotmail.com

Received: July 05, 2018; Accepted: December 03, 2018 was to determine whether the strengthening of the stapler line during LSG was beneficial.

\section{METHODOLOGY}

This experimental study was performed at the bariatric facilities of the Ortadogu Private Hospital in Adana, Turkey. One experienced surgeon performed all the LSGs between 2013 and 2017. All of the patients provided informed consent prior to undergoing LSG, and the local Ethics Committee approved the study. Based on their types of staple line reinforcement, the enrolled participants were placed in three groups of 63 subjects each as follows: group 1 - no reinforcement; group 2 - fibrin glue; and group 3 - barbed continued suture reinforcement. Based on the current guidelines for bariatric procedures according to the American Society for Metabolic and Bariatric Surgery, every patient underwent an initial evaluation and was followedup by an integrated team of specialised dietician, endocrinologist, and psychiatrist. The inclusion criteria were patients with $\mathrm{BMI}>40 \mathrm{Kg} / \mathrm{m}^{2}$ or $>35 \mathrm{Kg} / \mathrm{m}^{2}$ (if there were comorbid diseases associated with obesity). The exclusion criteria were patients who were older than 65 years or had a prior bariatric procedure.

A 5-trocar method was utilised. Using a 5-mm radiofrequency device (Ligasure TM, Covidien, Mansfield, MA, USA), the stomach's greater curvature was dissected free via the following procedure: first, ligasure 
was used to divide the vessels (short gastric), beginning on the other side of the Crow's foot and extending to the His angle. A $39 \mathrm{~F}$ bougie is used for calibration. The surgeon next transected the stomach by firing, in the following order 1) two linear black and 2) 3 or 4 purple GIA reloads, respectively $\left(60 \mathrm{~mm}\right.$, Endo $\mathrm{GIA}^{\mathrm{TM}}$ reinforced reload with Tri-Staple ${ }^{\mathrm{TM}}$, Medtronic $\AA$, Minneapolis, USA). Methylene-blue injection was done in order to detect any leaks. In group 2 (fibrin glue), two $8 \mathrm{ml}$ boxes of fibrin glue were sprayed (Easyspray ${ }^{\mathrm{TM}}$-Baxter@ Deerfield, IL, USA) down the line of the suture and posterior to the stomach (which was now sleeved). In group 3 (V lock), the staple line was reinforced using V-Loc ${ }^{\text {TM }} 90$ (Covidien, Mansfield, Ma).

For the current study, patient demographics (e.g., comorbid conditions, BMI, age, gender), and any postoperative complications were recorded.

To prevent thromboembolism, every patient was given 1-2 $\mathrm{mg} / \mathrm{kg}$ low MW heparin (subcutaneously) prior to the operation and throughout the next two weeks following surgery. The key primary outcomes included postoperative complications (e.g., stenosis, bleeding, leaks), and secondary measures included the total amount of time necessary to do the sleeve laparoscopic reinforcement (SLR) as well as the time of the overall operation. For group 2 (fibrin glue), SLR was defined as the amount of time elapsed from the final fired GIA staple reload to the final roofing for the whole SL, while in group 3, it was defined as the amount of time between the last fired GIA reload and the final $S L$ oversewing. The full duration of the surgery was defined as the elapsed time from the first incision until the wound was closed. On the third day postoperatively, every patient underwent a control Gastrographin X-ray (swallow). Any post-operative complications were determined during follow-up for one month. All procedures performed in studies involving human participants were in accordance with the ethical standards of the Institutional and/or National Research
Committee and with the 1964 Helsinki declaration and its later amendments or comparable ethical standards.

All statistical analyses were performed with the SPSS 23.0 package programme. Categorical measurements are presented as numbers and percentages, and continuous measurements are presented as means and standard deviations. Categorical variables were analysed with a Chi-square test or Fisher test. For comparisons of continuous measurements between groups, a one-way analysis of variance (Anova) was used for variables that were distributed parametrically, and a Kruskal Wallis test was used for those that were not. Values of $p<0.05$ were deemed significant for all analyses.

\section{RESULTS}

Patient demographics are presented in Table I. There were 45 male $(23.8 \%)$, and 144 female $(76.2 \%)$ patients. The average age of the participants in group 1 (no reinforcement) was $34.8 \pm 12.6$ years, $39.7 \pm 9.2$ years in group 2 (fibrin glue), and $38.7 \pm 13.7$ years in group 3 ( $\mathrm{V}$ lock). The average preoperative BMI was $45.0 \pm 2.6$ $\mathrm{Kg} / \mathrm{m}^{2}$ in group 1 (no reinforcement), $44.8 \pm 1.8$ in group 2 (fibrin glue), and $45.7 \pm 1.6$ in group 3 (V lock, $p>0.05$ ). Further, there were no statistical differences with regards to comorbid conditions among groups.

All procedures were performed laparoscopically. There was a significant statistical difference between the average time to complete SLR $(p<0.0001)$. Group 2 (fibrin glue) averaged 10 minutes (8-17 minutes), while group 3 ( $V$ lock) averaged a significantly higher 22 minutes (18-30 minutes).

Table II: LSG data and hospital duration.

\begin{tabular}{l|c|c|c|c}
\hline & $\begin{array}{c}\text { Group 1 } \\
\text { (No SLR) }\end{array}$ & $\begin{array}{c}\text { Group 2 } \\
\text { (Fibrin Glue) }\end{array}$ & $\begin{array}{c}\text { Group 3 } \\
\text { (V LOCK) }\end{array}$ & $\mathrm{p}$ \\
\hline Total operative time (min) & $70.8 \pm 5.4$ & $74.7 \pm 6.2$ & $81.2 \pm 3.0$ & 0.0001 \\
\hline Time for SLR (min) & - & $10(8-17)$ & $22(18-30)$ & 0.0001 \\
\hline Hospital duration* (days) & $3(3-4)$ & $3(3-4)$ & $3(3-4)$ & 0.869 \\
\hline
\end{tabular}

*Median (Min-Max)

Table I: Patient demographics.

\begin{tabular}{|c|c|c|c|c|c|c|c|}
\hline & \multicolumn{2}{|c|}{$\begin{array}{l}\text { No SLR } \\
\text { Group } 1\end{array}$} & \multicolumn{2}{|c|}{$\begin{array}{c}\text { Fibrin Glue } \\
\text { Group } 2\end{array}$} & \multicolumn{2}{|c|}{$\begin{array}{l}\text { Suture } \\
\text { Group } 3\end{array}$} & \multirow[t]{2}{*}{$\mathrm{p}$} \\
\hline & $\mathrm{n}$ & $\%$ & $\mathrm{n}$ & $\%$ & $\mathrm{n}$ & $\%$ & \\
\hline \multicolumn{8}{|l|}{ Gender } \\
\hline Male & 9 & 14.3 & 18 & 28.6 & 18 & 28.6 & 0.455 \\
\hline Female & 54 & 85.7 & 45 & 71.4 & 45 & 71.4 & \\
\hline \multicolumn{8}{|l|}{ Sleep Apnea } \\
\hline Present & 3 & 4.8 & 3 & 4.8 & 3 & 4.8 & 1.000 \\
\hline Absent & 60 & 95.2 & 60 & 95.2 & 60 & 95.2 & \\
\hline \multicolumn{8}{|l|}{ Hypertension } \\
\hline Present & 12 & 19.0 & 18 & 28.6 & 15 & 23.8 & 0.769 \\
\hline Absent & 51 & 81.0 & 45 & 71.4 & 48 & 76.2 & \\
\hline \multicolumn{8}{|c|}{ Diabetes Mellitus } \\
\hline Present & 6 & 9.5 & 9 & 14.3 & 9 & 14.3 & 0.867 \\
\hline Absent & 57 & 90.5 & 54 & 85.7 & 54 & 85.7 & \\
\hline BMI $\left(\mathrm{kg} / \mathrm{m}^{2}\right)$ & \multicolumn{2}{|c|}{$45.0 \pm 2.6$} & \multicolumn{2}{|c|}{$44.8 \pm 1.8$} & \multicolumn{2}{|c|}{$45.7 \pm 1.6$} & 0.334 \\
\hline Age (years) & \multicolumn{2}{|c|}{$34.8 \pm 12.6$} & \multicolumn{2}{|c|}{$39.7 \pm 9.2$} & \multicolumn{2}{|c|}{$38.7 \pm 13.7$} & 0.384 \\
\hline
\end{tabular}


In addition, there were significant differences with regard to the average total operative time $(p<0.001)$. Group 1 (no reinforcement) had an average time of $70.8 \pm 5.4$ minutes, while group 2 (fibrin glue) was operated 74.7 \pm 6.2 minutes and group 3 ( $V$ lock) in $81.2 \pm 3.0$ minutes. As shown in Table II, staple-line reinforcement significantly increased the time of the total operation. The average postoperative hospital stay was three days (range 3-4) for each group (Table II).

Throughout the study, there were no intraoperative complications or postoperative mortality. In addition, the methylene-blue test did not reveal any intraoperative leaks. However, one patient in group 3 (V lock) experienced postoperative bleeding, which stopped without the need for blood transfusion. Further, none of the patients in the current study experienced any postoperative leaks, stenosis, or stricture.

\section{DISCUSSION}

Although LSG is now more popular, advantageous, and used more frequently than other bariatric techniques, it has major complications, such as bleeding and leakage. Therefore, most surgeons use staple line reinforcement and other materials to reduce leaks and bleeding. However, some authors argue that staple line reinforcement is an unnecessary procedure. 8,16 There is no consensus regarding staple line reinforcement in the literature. ${ }^{17}$ In a review of 88 studies including a total of 820 patients, Gagner et al. detected that the risk of leakage is significantly lower when absorbable polymer membrane is used. ${ }^{8}$ These buttressing materials can be very costly, and surgeons often experience difficulty when placing them. While it is challenging to standardise these buttressing materials and their use, it should be noted that none of them can prevent all leakages. Therefore, suturing is an alternative choice that is commonly used to avoid staple-line leaks. ${ }^{12}$

There are also some disadvantages of using sutures as a staple line reinforcement, including stenosis, hemorrhage, ischemia, and hematoma. More importantly, studies have found that sutures fail to reduce the risk of leakage. In our study, there were no differences regarding postoperative leaks, bleeding, and stenosis when the V-Loc ${ }^{\mathrm{TM}}$ running suture was used as SLR during LSG. Literature suggests that proper surgical techniques and the correct staples should lead to low leak rates.2,15,18

The FDA approved fibrin sealant for the reinforcement of staple lines. So far, it has been described as the lone sealant that can lead to adhesion, sealing, and hemostasis. ${ }^{19}$ While several different surgical procedures have been shown to safely and effectively use fibrin sealant, there are limited studies utilising this method for SLR in LSG. However, the data that has been published is encouraging. 20 In the current study, human fibrin sealant was used as an SLR during LSG. Using this method, there were no differences in postoperative leaks, bleeding, and stenosis. Likewise, a prospective randomised study by Carandi et al. also revealed that fibrin glue had no significance in terms of postoperative bleeding and leakage and that its use extended the operation time. ${ }^{11}$ Although, Coskun et al. indicated that fibrin glue is useful, however, it was not compared with a control group. ${ }^{12}$ The prospective randomised study by Gentileschi et al. compared oversewing, fibrin glue, and buttressing for SLR in LSG. That study indicated that fibrin glue was just as safe as oversewing and buttressing. ${ }^{21}$

In this study, both staple line reinforcement methods significantly prolonged the operation time. The number of cases is limited and a larger series is needed to document the incidence of complication of leakage for which these alternate modalities are being evaluated.

\section{CONCLUSION}

Human fibrin sealant, running suture, and no reinforcement, had no significant differences in post-operative leaks, bleeding, and stenosis.

\section{REFERENCES}

1. Brethauer SA, Hammel JP, Schauer PR. Systematic review of sleeve gastrectomy as staging and primary bariatric procedure. Surg Obes Relat Dis 2009; 5:469-75.

2. Parikh M, Issa R, McCrillis A, Saunders JK, Ude-Welcome A, Gagner M. Surgical strategies that may decrease leak after laparoscopic sleeve gastrectomy: A systematic review and meta-analysis of 9991 cases. Ann Surg 2013; 257:231-7.

3. Sarela Al, Dexter SP, O'Kane M, Menon A, McMahon MJ. Long-term follow-up after laparoscopic sleeve gastrectomy: 8-9-year results. Surg Obes Relat Dis 2012; 8:679-84.

4. Todkar JS, Shah SS, Shah PS, Gangwani J. Long-term effects of laparoscopic sleeve gastrectomy in morbidly obese subjects with type 2 diabetes mellitus. Surg Obes Relat Dis 2010; 6:142-5.

5. Almogy G, Crookes PF, Anthone GJ. Longitudinal gastrectomy as a treatment for the high-risk super-obese patient. Obes Surg 2004; 14:492-7.

6. Cottam D, Qureshi FG, Mattar SG, Sharma S, Holover S, Bonanomi G, et al. Laparoscopic sleeve gastrectomy as an initial weight-loss procedure for high-risk patients with morbid obesity. Surg Endosc 2006; 20:859-63.

7. Regan JP, Inabnet WB, Gagner M, Pomp A. Early experience with two-stage laparoscopic Roux-en-Y gastric bypass as an alternative in the super-super obese patient. Obes Surg 2003; 13:861-4.

8. Gagner M, Buchwald JN. Comparison of laparoscopic sleeve gastrectomy leak rates in four staple-line reinforcement options: A systematic review. Surg Obes Relat Dis 2014; 10:713-23.

9. Aurora AR, Khaitan L, Saber AA. Sleeve gastrectomy and the risk of leak: A systematic analysis of 4,888 patients. Surg Endosc 2012; 26:1509-15. 
10. Musella M, Milone M, Maietta P, Bianco P, Pisapia A, Gaudioso D. Laparoscopic sleeve gastrectomy: Efficacy of fibrin sealant in reducing postoperative bleeding. A randomized controlled trial. Updates Surg 2014; 66:197-201.

11. Carandina S, Tabbara M, Bossi M, Valenti A, Polliand C, Genser $L$, et al. Staple line reinforcement during laparoscopic sleeve gastrectomy: Absorbable monofilament, barbed suture, fibrin glue, or nothing? Results of a prospective randomized study. J Gastrointest Surg 2016; 20:361-6.

12. Coskun $\mathrm{H}$, Yardimci E. Effects and results of fibrin sealant use in 1000 laparoscopic sleeve gastrectomy cases. Surg Endosc 2017; 31:2174-9.

13. Rogula T, Khorgami Z, Bazan M, Mamolea C, Acquafresca P, El-Shazly $\mathrm{O}$, et al. Comparison of reinforcement techniques using suture on staple-line in sleeve gastrectomy. Obes Surg 2015; 25:2219-24.

14. Shah SS, Todkar JS, Shah PS. Buttressing the staple line: A randomized comparison between staple-line reinforcement versus no reinforcement during sleeve gastrectomy. Obes Surg 2014; 24:2014-20.

15. Baker RS, Foote J, Kemmeter P, Brady R, Vroegop T, Serveld M. The science of stapling and leaks. Obes Surg 2004; 14:1290-8.
16. Chen B, Kiriakopoulos A, Tsakayannis D, Wachtel MS, Linos D, Frezza EE. Reinforcement does not necessarily reduce the rate of staple line leaks after sleeve gastrectomy. A review of the literature and clinical experiences. Obes Surg 2009; 19:166-72.

17. Choi YY, Bae J, Hur KY, Choi D, Kim YJ. Reinforcing the staple line during laparoscopic sleeve gastrectomy: does it have advantages? A meta-analysis. Obes Surg 2012; 22:1206-13.

18. D'Hondt M, Vanneste S, Pottel H, Devriendt D, Van Rooy F, Vansteenkiste F. Laparoscopic sleeve gastrectomy as a singlestage procedure for the treatment of morbid obesity and the resulting quality of life, resolution of comorbidities, food tolerance, and 6-year weight loss. Surg Endosc 2011; 25:2498-504.

19. Spotnitz WD. Fibrin sealant: The only approved hemostat, sealant, and adhesive - a laboratory and clinical perspective. ISRN Surg 2014; 2014:203943.

20. Bellanger DE, Greenway FL. Laparoscopic sleeve gastrectomy, 529 cases without a leak: Short-term results and technical considerations. Obes Surg 2011; 21:146-50.

21. Gentileschi P, Camperchioli I, D'Ugo S, Benavoli D, Gaspari AL. Staple-line reinforcement during laparoscopic sleeve gastrectomy using three different techniques: A randomized trial. Surg Endosc 2012; 26:2623-9. 